\title{
Robust nonlinear control of wind turbine driven doubly fed induction generators
}

\author{
Youcef Djeriri $^{1}$, Hamza Mesai Ahmed ${ }^{1}$ \\ ${ }^{1}$ Laboratory ICEPS, Djillali Liabes University Sidi-Bel-Abbes, Algeria
}

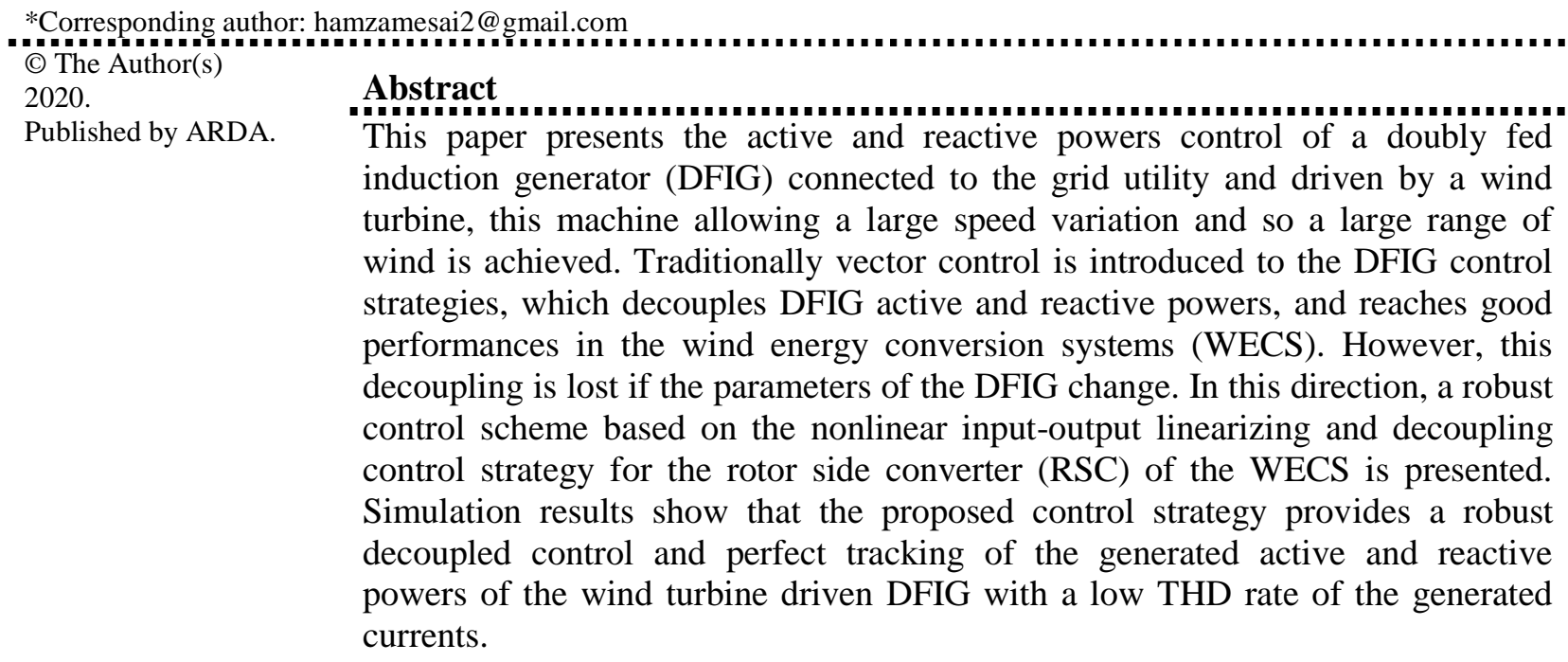

Keywords: Wind energy, doubly fed induction generator, input-output linearizing control, robustness.

\section{Introduction}

Due to the economic impact of wind power, efficient control techniques are becoming a focus of the world's renewable energy challenges, making it a promising field of study. With better controllers and the constant development of new technologies, wind power will maintain its rapidly growing market ratio.

In recent years, the concept of the variable speed wind turbine (VSWT) equipped with a doubly fed induction generator (DFIG) has received increasing attention due to its noticeable advantages over other wind turbine concepts [1]. In the DFIG concept, the stator is usually connected directly to the three-phase grid; the rotor is also connected to the grid but via a transformer and two back-to-back converters (Fig. 1).

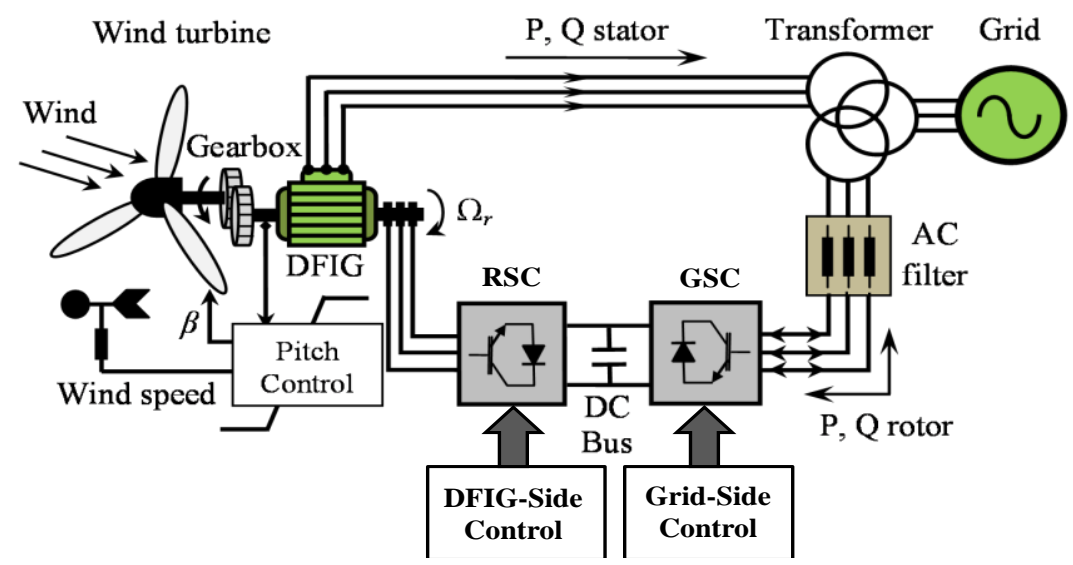

Figure 1. Wind energy conversion system based a DFIG 
This arrangement provides a flexibility of operation in sub and super-synchronous speeds in both generating and motoring modes $( \pm 30 \%$ around the synchronous speed). The power inverter needs to handle a fraction (20-30\%) of the total power to achieve full control of the generator.

Recently, several nonlinear controls laws based a DFIG are presented in literatures such as sliding mode control (SMC) technique [2], [3]. However, the major problem of this strategy of control is the chattering phenomenon caused by the control switching, which may have undesirable effects on the machine, such as overheating of the windings, torque pulsation, current harmonics, acoustic noise, etc. [4].

This paper discusses the synthesis of a multivariable nonlinear controller by input-output linearizing technique for the control of a doubly fed induction generator dedicated to a wind turbine system. The objective is to the modeling and control of a wind conversion system based on DFIG, associated with a control of active and reactive power based on stator flux orientation. This technique is applied to the rotor side converter (RSC) in both sub and super-synchronous mode operation of DFIG. Finally, the simulation results will be analyzed in terms of robustness against parameters variations of the DFIG and the quality of energy supplied to the grid.

\section{Mathematical model of DFIG}

The equivalent circuit of the DFIG in the synchronous reference frame rotating at the angular synchronous speed $\omega_{s}$ is shown in Fig. 2.

The model of the DFIG in the synchronous $d-q$ reference frame is given by the following equations:

Stator voltage components:

$$
\left\{\begin{array}{l}
V_{d s}=R_{s} I_{d s}+\frac{d}{d t} \psi_{d s}-\omega_{s} \psi_{q s} \\
V_{q s}=R_{s} I_{q s}+\frac{d}{d t} \psi_{q s}+\omega_{s} \psi_{d s}
\end{array}\right.
$$

Rotor voltage components:

$$
\left\{\begin{array}{l}
V_{d r}=R_{r} I_{d r}+\frac{d}{d t} \psi_{d r}-\left(\omega_{s}-\omega_{r}\right) \psi_{q r} \\
V_{q r}=R_{r} I_{q r}+\frac{d}{d t} \psi_{q r}+\left(\omega_{s}-\omega_{r}\right) \psi_{d r}
\end{array}\right.
$$

Stator flux components:

$$
\left\{\begin{array}{l}
\psi_{d s}=L_{s} I_{d s}+L_{m} I_{d r} \\
\psi_{q s}=L_{s} I_{q s}+L_{m} I_{q r}
\end{array}\right.
$$

Rotor flux components:

$$
\left\{\begin{array}{l}
\psi_{d r}=L_{r} I_{d r}+L_{m} I_{d s} \\
\psi_{q r}=L_{r} I_{q r}+L_{m} I_{q s}
\end{array}\right.
$$

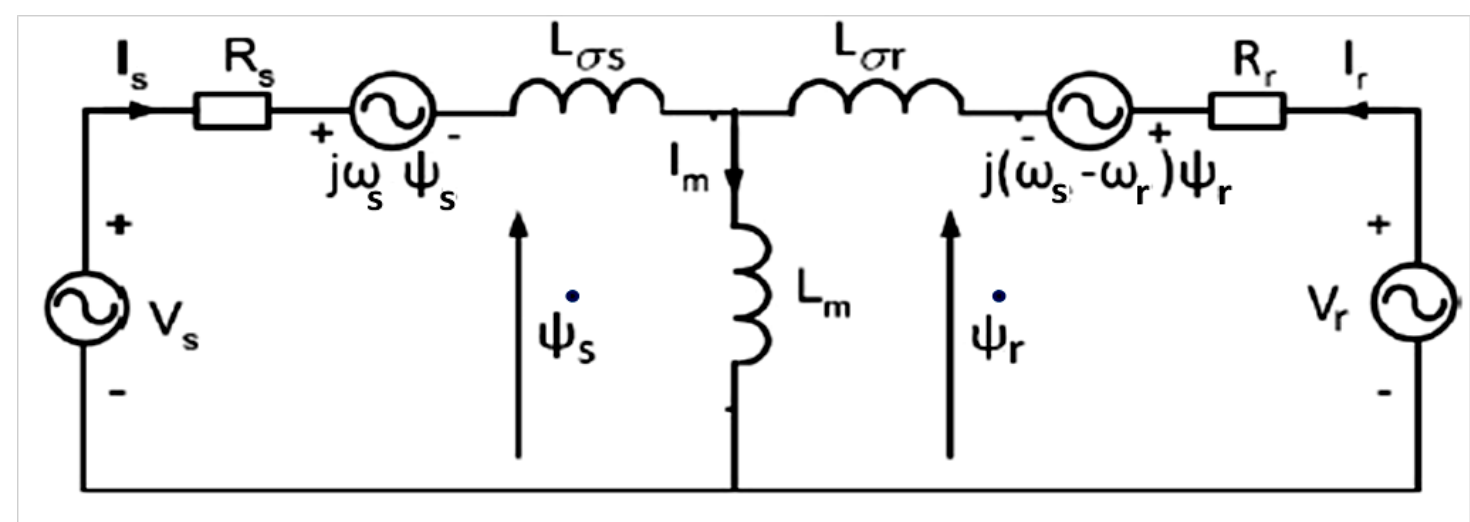

Figure 2. DFIG equivalent circuit in the synchronous reference frame 
DFIG electromagnetic torque:

$$
T_{e m}=\frac{3}{2} p \frac{L_{m}}{L_{s}}\left(\psi_{q s} I_{d r}-\psi_{d s} I_{q r}\right)
$$

Mechanical equation:

$$
T_{t}=T_{e m}+J \frac{d \Omega_{r}}{d t}+f_{r} \Omega_{r}
$$

The active and reactive powers at the stator side of DFIG are given by the expressions:

$$
\left\{\begin{array}{l}
P_{s}=\frac{3}{2}\left(V_{d s} I_{d s}+V_{q s} I_{q s}\right) \\
Q_{s}=\frac{3}{2}\left(V_{q s} I_{d s}-V_{d s} I_{q s}\right)
\end{array}\right.
$$

The rotor-side converter is controlled in a synchronously rotating $d$-q axis frame, with the $d$-axis oriented along the stator flux vector position (Fig. 3).

The influence of the stator resistance can be neglected and the stator flux can be held constant as the stator is connected to the grid. Consequently:

$$
\left\{\begin{array}{l}
\psi_{d s}=\psi_{s} \\
\psi_{q s}=0
\end{array}\right.
$$

Since the stator is directly connected to the grid and the stator flux can be considered constant, and if the voltage dropped in the stator resistance has been neglected [5], the stator voltage equations, flux equations, currents equations and stator active and reactive powers equations can be respectively simplified in study state as:

$$
\begin{aligned}
& \left\{\begin{array}{l}
V_{d s}=0 \\
V_{q s}=V_{s}=\omega_{s} \cdot \psi_{s}
\end{array}\right. \\
& \left\{\begin{array}{l}
\psi_{s}=L_{s} I_{d s}+L_{m} I_{d r} \\
0=L_{s} I_{q s}+L_{m} I_{q r}
\end{array}\right. \\
& \left\{\begin{array}{l}
I_{d s}=\frac{\psi_{s}}{L_{s}}-\frac{L_{m}}{L_{r}} I_{d r} \\
I_{q s}=-\frac{L_{m}}{L_{s}} I_{q r}
\end{array}\right.
\end{aligned}
$$

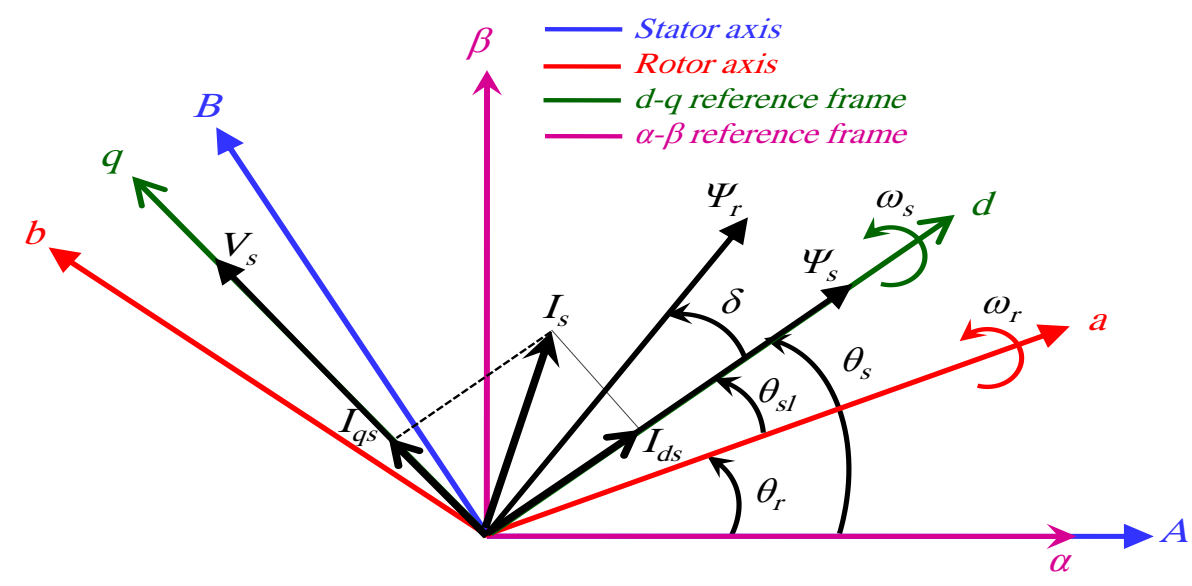

Figure 3. Stator field-oriented control technique 


$$
\left\{\begin{array}{l}
P_{s}=\frac{3}{2} V_{s} I_{q s} \\
Q_{s}=\frac{3}{2} V_{s} I_{d s}
\end{array}\right.
$$

Replacing the stator currents by their expressions given in (11), the equations below are expressed by:

$$
\left\{\begin{array}{l}
P_{s}=-\frac{3}{2} \frac{L_{m}}{L_{s}} V_{s} I_{q r} \\
Q_{s}=\frac{3}{2} V_{s}\left(\frac{V_{s}}{L_{s} \cdot \omega_{s}}-\frac{L_{m}}{L_{s}} I_{d r}\right)
\end{array}\right.
$$

The electromagnetic torque is as follows:

$$
T_{e m}=-\frac{3}{2} p \frac{L_{m}}{L_{s}} \psi_{s} I_{q r}
$$

\section{General concept of the input-output linearizing control strategy}

\subsection{Lie derivative}

Given the system [4]:

$$
\left\{\begin{array}{l}
\dot{x}=f(x)+g(x) u \\
y=h(x)
\end{array}\right.
$$

Where " $x$ " is the state vector; " $u$ " is the input; " $y$ " is the output; " $f$ " and " $g$ " are smooth vector fields; " $h$ " is smooth scalar function.

The Lie derivative of the function $h(x)$ along a vector field $f^{T}(x)=\left(f_{l}(x), f_{2}(x), \ldots, f_{n}(x)\right)$ is given by [7]:

$$
L_{f} h(x)=\sum_{i=1}^{n} \frac{\partial h(x)}{\partial x_{i}} f_{i}(x)
$$

Where $L_{f} h(x)$ is a derivative of Lie its means: the derivative of $h(x)$ in the direction of $f$.

The purpose of the linearization application is to find a nonlinear feedback control as the following form:

$$
v=\alpha(x)+\beta(x) u
$$

This brings the nonlinear system in closed-loop back to a linear system. This makes it possible to obtain a linear behavior of the system over the entire operating range, unlike the vector control that linearizes the system around an operating point.

\subsection{Relative degree}

The relative degree " $r$ " of the output " $y$ ", is the number of times it is necessary to derive " $y$ " to make the input " $u$ " explicitly appear in the derivatives of " $y$ ".

According to this definition we can say that:

The system in (23) is said to have a relative degree " $r$ " if:

$$
\begin{aligned}
& \forall x \in R: L_{g} L_{f}^{(k)} h(x)=0 ; k<r-1 \\
& \text { and }: L_{g} L_{f}^{(r-1)} h(x) \neq 0
\end{aligned}
$$

Indeed, if we apply this principle to the system in (15), we obtain: 


$$
\left\{\begin{array}{l}
\dot{y}=\frac{d y}{d t}=\frac{d y}{d x} \frac{d x}{d t}=\frac{d h}{d x} \dot{x} \\
\dot{y}=\frac{d h(x)}{d x}(f(x)+g(x) u) \\
\dot{y}=L_{f} h(x)+L_{g} h(x) u
\end{array}\right.
$$

If $L_{f} h(x)=0$, we continue the derivation of the output " $y$ " until the appearance of " $u$ " for the first time, for a relative degree equal to " $r$ ", we obtain:

$$
\left\{\begin{array}{l}
y=h(x) \\
\dot{y}=L_{f} h(x) \\
\quad \vdots \\
y^{(r)}=L_{f}^{(r)} h(x)+L_{g} L_{f}^{(r-1)} h(x) u
\end{array}\right.
$$

The input-output relation of the system in (15) is therefore the following [8]:

$$
y^{(r)}=L_{f}^{(r)} h(x)+L_{g} L_{f}^{(r-1)} h(x) u
$$

\subsection{Multivariable input-output linearization}

Considering now a system with " $p$ " inputs and " $p$ " outputs given by:

$$
\left\{\begin{array}{l}
\dot{x}=f(x)+g_{1}(x) u_{1}+\cdots+g_{P}(x) u_{p}=f(x)+\sum_{\mathbf{i}=\mathbf{1}}^{\mathbf{p}} g_{i}(x) u_{i} \\
y_{1}=h_{1}(x) \\
\quad \vdots \\
y_{p}=h_{p}(x)
\end{array}\right.
$$

Where:

$x=\left[x_{1}, \ldots, x_{n}\right]^{T} \in R^{n}:$ is the state vector where $\mathrm{n}$ is the order of the system;

$U=\left[u_{1}, \ldots, u_{p}\right]^{T} \in R^{p}:$ is the vector of control input signals;

$Y=\left[y_{1}, \ldots, y_{p}\right]^{T} \in R^{p}:$ is the vector of the output signals;

$f(x) \in R^{n}, g_{\mathrm{i}}(x) \in R^{n x p}$ and $h_{i}(x) \in R^{p}, i=1, \ldots, p$, are differentiable functions.

If the system to be linearized admits the vector of relative degrees $r=\left[r_{1}, \ldots, r_{p}\right]^{T} \in R^{p}$, then the inputoutput differential equations of the system are given by:

$$
y_{i}^{(r i)}=L_{f}^{r_{i}} h_{i}+\sum_{j=1}^{p} L_{g_{j}}\left(L_{f}^{r_{j}-1} h_{i}\right) u_{i}
$$

With at least one of the $L_{g_{j}}\left(L_{f}^{r_{i}-1} h_{i}\right) \neq 0$.

We can write the input-output equations of the system in matrix form as follows: 


$$
\left[\begin{array}{c}
y_{1}^{r_{1}} \\
\vdots \\
y_{p}^{r_{\mathrm{p}}}
\end{array}\right]=\left[\begin{array}{c}
L_{\mathrm{f}}^{r_{1}} h_{1} \\
\vdots \\
L_{f}^{r_{\mathrm{p}}} h_{p}
\end{array}\right]+\left[\begin{array}{ccc}
L_{g_{1}} L_{f}^{r_{1}-1} h_{1} & \cdots & L_{g_{p}} L_{f}^{r_{1}-1} h_{1} \\
\vdots & \ddots & \vdots \\
L_{g_{1}} L_{f}^{r_{\mathrm{p}-1}} h_{p} & \cdots & L_{g_{p}} L_{f}^{r_{\mathrm{p}-1}} h_{p}
\end{array}\right]\left[\begin{array}{c}
u_{1} \\
\vdots \\
u_{p}
\end{array}\right]
$$

Or:

$$
Y^{(r)}=A(x)+D(x) \cdot U
$$

Where:

$$
A(x)=\left[\begin{array}{c}
L_{f}^{r_{1}} h_{1} \\
\vdots \\
L_{f}^{r_{p}} h_{p}
\end{array}\right] \text { and } D(x)=\left[\begin{array}{ccc}
L_{g_{1}} L_{f}^{r_{1}-1} h_{1} & \cdots & L_{g_{p}} L_{f}^{r_{1}-1} h_{1} \\
\vdots & \ddots & \vdots \\
L_{g_{1}} L_{f}^{r_{\mathrm{p}-1}} h_{p} & \cdots & L_{g_{p}} L_{f}^{r_{\mathrm{p}-1}} h_{p}
\end{array}\right]
$$

$A(X) \in R^{p}:$ is called loopback matrix.

$D(X) \in R^{p x p}$ : is called decoupling matrix, it must be non-singular ( $\mathrm{D}^{-1}$ exists).

To linearize the system, we define the linearizing control law: $U=\left[u_{1}, \ldots, u_{p}\right]^{T}$, such that $[6,8]$ :

$$
U=D^{-1}(-A+v)
$$

Where:

$v=\left[v_{1}, \ldots, v_{p}\right]^{T}:$ is the new control input vector of the system to be linearized.

Then the system in (24) becomes:

$$
\left[\begin{array}{c}
y_{1}^{r_{\mathrm{i}}} \\
\vdots \\
y_{p}^{r_{\mathrm{p}}}
\end{array}\right]=\left[\begin{array}{c}
\mathrm{L}_{\mathrm{f}}^{r_{\mathrm{i}}} h_{1} \\
\vdots \\
L_{f}^{r_{\mathrm{p}}} h_{p}
\end{array}\right]+D(x)\left[\begin{array}{c}
u_{1} \\
\vdots \\
u_{p}
\end{array}\right]
$$

If the linearization and uncoupling control law of the system is given by:

$$
\left[\begin{array}{c}
u_{1} \\
\vdots \\
u_{p}
\end{array}\right]=D^{-1}(x)\left[\left[\begin{array}{c}
-\mathrm{L}_{\mathrm{f}}^{r_{\mathrm{i}}} h_{1} \\
\vdots \\
-L_{\mathrm{f}}^{r_{\mathrm{p}}} h_{p}
\end{array}\right]+\left[\begin{array}{c}
v_{1} \\
\vdots \\
v_{p}
\end{array}\right]\right]
$$

Then the system becomes in closed loop as follows:

$$
\left[\begin{array}{c}
y_{1}^{\left(r_{1}\right)} \\
\vdots \\
y_{p}^{\left(r_{p}\right)}
\end{array}\right]=\left[\begin{array}{c}
v_{1} \\
\vdots \\
v_{p}
\end{array}\right]
$$

\section{Input-output linearizing control of the DFIG}

The active and reactive powers of the DFIG are controlled by the rotor current that is controlled through the output voltage of the rotor side converter. Therefore, the applied voltage of the rotor is the direct control variable. 
According to the (11) the direct and quadrature components of stator and rotor currents are linear dependent respectively, thus we choose the state vector of the DFIG as follows:

$$
x=\left[\begin{array}{ll}
x_{1} & x_{2}
\end{array}\right]^{T}=\left[\begin{array}{ll}
I_{d r} & I_{q r}
\end{array}\right]^{T}
$$

The Input variables are the rotor voltages:

$$
u=\left[\begin{array}{ll}
u_{1} & u_{2}
\end{array}\right]^{T}=\left[\begin{array}{ll}
V_{d r} & V_{q r}
\end{array}\right]^{T}
$$

The output variables are the active and reactive stator powers:

$$
x=\left[\begin{array}{l}
y_{1} \\
y_{2}
\end{array}\right]=\left[\begin{array}{l}
h_{1}(x) \\
h_{2}(x)
\end{array}\right]=\left[\begin{array}{l}
P_{s} \\
Q_{s}
\end{array}\right]
$$

The expressions of active and reactive power are:

$$
\left\{\begin{array}{l}
y_{1}=h_{1}(x)=-\frac{3}{2} \frac{L_{m}}{L_{s}} V_{s} I_{q r} \\
y_{2}=h_{2}(x)=-\frac{3}{2} \frac{L_{m}}{L_{s}} V_{s} I_{d r}+\left(\frac{3 V_{s}^{2}}{2 L_{s} \cdot \omega_{s}}\right)
\end{array}\right.
$$

Hence the derivative of the outputs is given by:

$$
\left\{\begin{array}{l}
\dot{y}_{1}=\dot{h}_{1}(x)=-\frac{3}{2} \frac{L_{m}}{L_{s}} V_{s} \dot{I}_{q r} \\
\dot{y}_{2}=\dot{h}_{2}(x)=-\frac{3}{2} \frac{L_{m}}{L_{s}} V_{s} \dot{I}_{d r}
\end{array}\right.
$$

Where:

$$
\left\{\begin{array}{l}
\dot{I}_{d r}=\frac{d I_{d r}}{d t} \\
\dot{I}_{q r}=\frac{d I_{q r}}{d t}
\end{array}\right.
$$

By substituting (11) to (4), we find:

$$
\left\{\begin{array}{l}
\psi_{d r}=\sigma L_{r} I_{d r}+\frac{L_{m}}{L_{s}} \Psi_{s} \\
\psi_{q r}=\sigma L_{r} I_{q r}
\end{array}\right.
$$

Where: $\sigma=1-\left(L_{m}^{2} / L_{s} L_{r}\right)$ : is the dispersion coefficient of Blondel.

By replacing (36) in (2), the following equations hold:

$$
\left\{\begin{array}{l}
V_{d r}=R_{r} I_{d r}+\sigma L_{r} \frac{d}{d t} I_{d r}-g \omega_{s} \sigma L_{r} I_{q r} \\
V_{q r}=R_{r} I_{q r}+\sigma L_{r} \frac{d}{d t} I_{q r}+g \omega_{s} \sigma L_{r} I_{d r}+\frac{g L_{m} V_{s}}{L_{s}}
\end{array}\right.
$$

Arranging (37) in the form of (11) as following: 


$$
\left\{\begin{array}{l}
\frac{d I_{d r}}{d t}=-\frac{R_{r}}{\sigma L_{r}} I_{d r}+g \omega_{s} I_{q r}+\frac{V_{d r}}{\sigma L_{r}} \\
\frac{d I_{q r}}{d t}=-g \omega_{s} I_{d r}-\frac{R_{r}}{\sigma L_{r}} I_{q r}-\frac{g L_{m} V_{s}}{\sigma L_{s} L_{r}}+\frac{V_{q r}}{\sigma L_{r}}
\end{array}\right.
$$

From (38), we have:

$$
\left\{\begin{array}{l}
f_{1}(x)=-\frac{R_{r}}{\sigma L_{r}} I_{d r}+g \omega_{s} I_{q r} \\
f_{2}(x)=-g \omega_{s} I_{d r}-\frac{R_{r}}{\sigma L_{r}} I_{q r}-\frac{g L_{m} V_{s}}{\sigma L_{s} L_{r}}
\end{array}\right.
$$

And:

$$
g=\left[\begin{array}{cc}
g_{1}(x) & 0 \\
0 & g_{2}(x)
\end{array}\right]=\left[\begin{array}{cc}
\frac{1}{\sigma L_{r}} & 0 \\
0 & \frac{1}{\sigma L_{r}}
\end{array}\right]
$$

We replace (39) in (34), and then we find:

$$
\left\{\begin{array}{l}
\dot{y}_{1}=\dot{h}_{1}(x)=-\frac{3}{2} \frac{L_{m}}{L_{s}} V_{s}\left(f_{2}+\frac{V_{q r}}{\sigma L_{r}}\right) \\
\dot{y}_{2}=\dot{h}_{2}(x)=-\frac{3}{2} \frac{L_{m}}{L_{s}} V_{s}\left(f_{1}+\frac{V_{d r}}{\sigma L_{r}}\right)
\end{array}\right.
$$

We can rewrite (41) in the form:

$$
\left[\begin{array}{l}
\dot{y_{1}} \\
\dot{y}_{2}
\end{array}\right]=A(x)+D(x)\left[\begin{array}{l}
u_{2} \\
u_{1}
\end{array}\right]
$$

Where:

$$
\begin{aligned}
& A(x)=-\frac{3}{2}\left[\begin{array}{c}
V_{s} \frac{L_{m}}{L_{s}} f_{2}(x) \\
V_{s} \frac{L_{m}}{L_{s}} f_{1}(x)
\end{array}\right] \\
& D(x)=-\frac{3}{2}\left[\begin{array}{cc}
0 & \frac{L_{m}}{\sigma L_{s} L_{r}} V_{s} \\
\frac{L_{m}}{\sigma L_{s} L_{r}} V_{s} & 0
\end{array}\right]
\end{aligned}
$$

Since the decoupling matrix $D(x)$ is nonsingular, the control law is given as:

$$
\left[\begin{array}{c}
V_{d r} \\
V_{q r}
\end{array}\right]=D^{-1}(x)\left[-A(x)+\left[\begin{array}{l}
v_{2} \\
v_{1}
\end{array}\right]\right]
$$

The Proportional-Integral (PI) controller achieves the tracking of the stator powers. Hence, the new input " $v$ " is given by $[6,9]$ : 


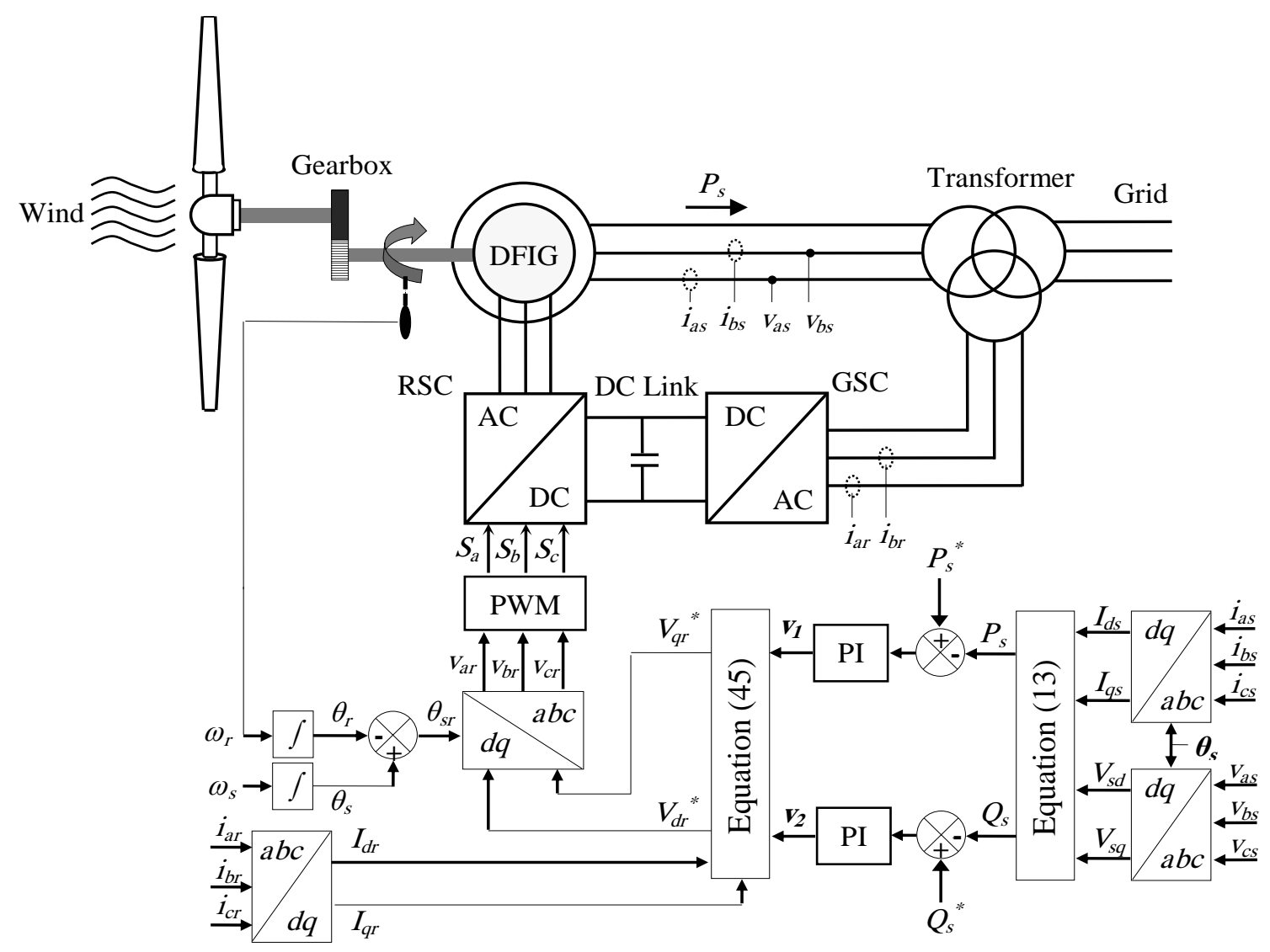

Figure 4. Block diagram of the input-output linearizing control of the DFIG

$$
\left[\begin{array}{l}
v_{1} \\
v_{2}
\end{array}\right]=\left[\begin{array}{l}
\dot{y}_{1}^{*}-k_{p 1} e_{1}-k_{i 1} \int e_{1} d t \\
\dot{y}_{2}^{*}-k_{p 2} e_{2}-k_{i 2} \int e_{2} d t
\end{array}\right]
$$

Where $e_{1}$ is the error between the desired and the measured active power, and $e_{2}$ is that relates to the reactive power:

$$
\left\{\begin{array}{l}
e_{1}=y_{1}^{*}-y_{1}=P_{s}^{*}-P_{s} \\
e_{2}=y_{2}^{*}-y_{2}=Q_{s}^{*}-Q_{s}
\end{array}\right.
$$

The block diagram of the input output linearizing control of the DFIG is represented by the Fig. 4.

\section{Simulation results and discussions}

In this section, the input-output linearizing control of 1.5MW DFIG (see appendix) is tested by simulation under Matlab/ Simulink software. Two types of tests were applied to the wind energy conversion system to observe the behavior of its regulation:

1- References tracking test at variable wind speed.

2- Robustness test against the parameters variations of the DFIG at fixed wind speed.

\subsection{References tracking test}

In this test, the wind turbine is driven by a variable wind speed with an average value of $8.2 \mathrm{~m} / \mathrm{sec}$ (Fig. 5.a). The reference active power is generated by the MPPT strategy and the reactive power reference is kept at zero in order to guarantee a unit power factor on the stator side of the DFIG (Fig. 5). 


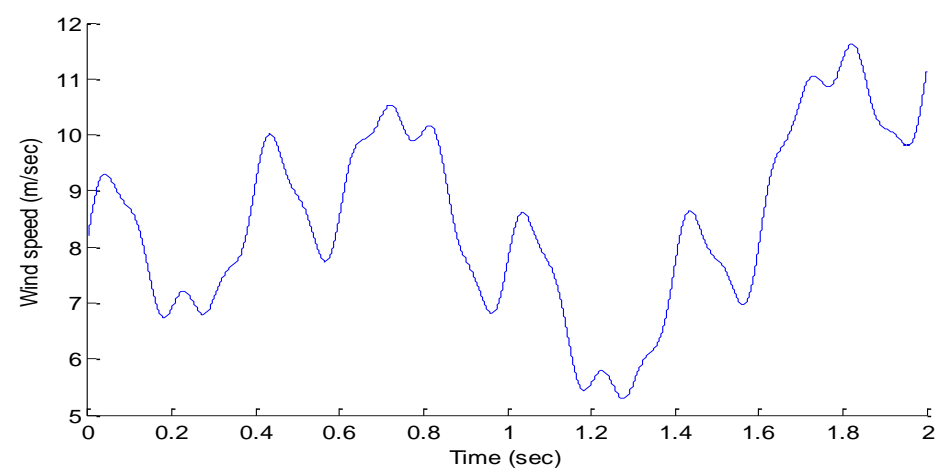

(a) wind speed

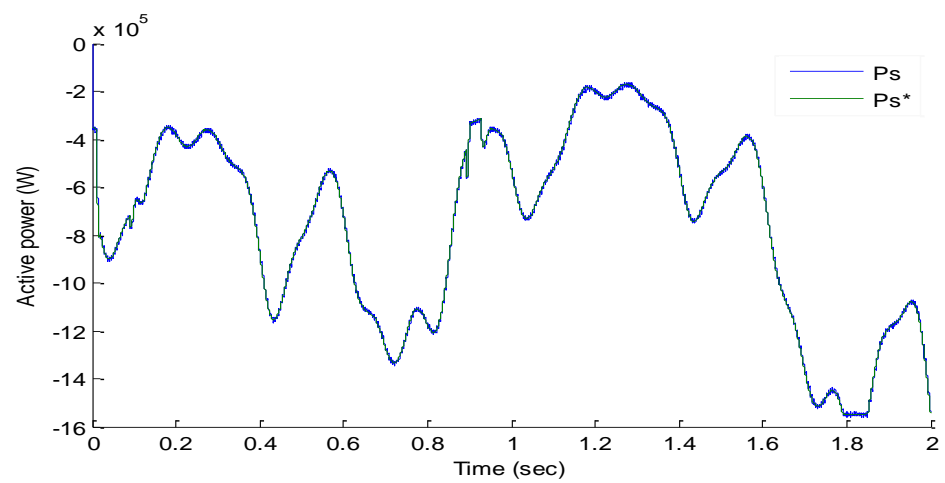

(b) active power response

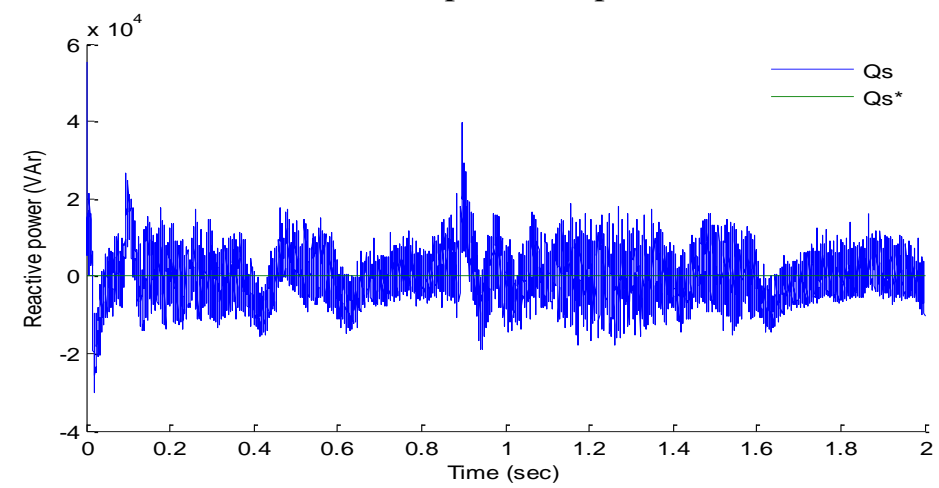

(c) reactive power response

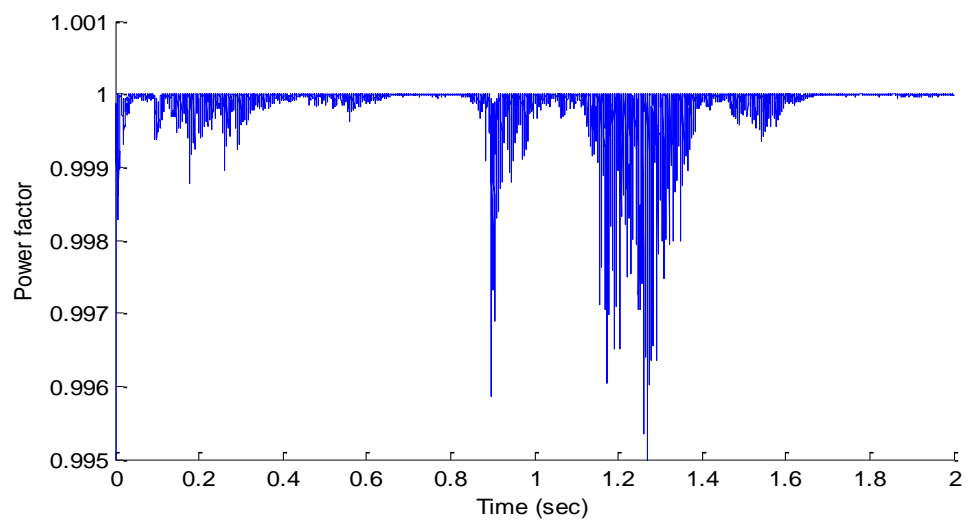

(d) power factor response

Figure 5. Simulation results of the input-output linearization control of DFIG

Fig. 5.b shows a very fast response of the active power, where it follows perfectly its reference generated by the MPPT strategy with a negligible error. The reactive power is maintained at its reference equal to zero (Fig. 
5.c), in order to achieve a unit power factor $(\mathrm{FP}=1)$ on the stator side of the DFIG (Fig. 5.c). The spectral analysis of the stator current shows that the input-output linearizing control of DFIG guarantees a better quality of the stator current waveform injected to the grid, where the total harmonic distortion (THD) rate is only $1.93 \%$.

\subsection{Robustness test}

In order to test the robustness of the proposed control strategy of the DFIG, we also studied the influence of parameters variations of the generator on the performances of this last one.

To realize this test we increase the rotor resistance $R_{r}$ by $100 \%$ of its nominal value (case of warming-up of rotor windings) and decrease the mutual inductance $L_{m}$ by $50 \%$ of its nominal value (case of inductances saturation).

Fig. 6 shows the active and reactive powers responses of DFIG for the input-output linearization control, whose the wind turbine is driven at fixed wind speed of $12 \mathrm{~m} / \mathrm{sec}$.

Simulation results in Fig. 6 show the robustness of the proposed control strategy against parameters variations of the DFIG, contrary to the vector control strategy (FOC) based PI (Proportional-Integral) controllers [10].

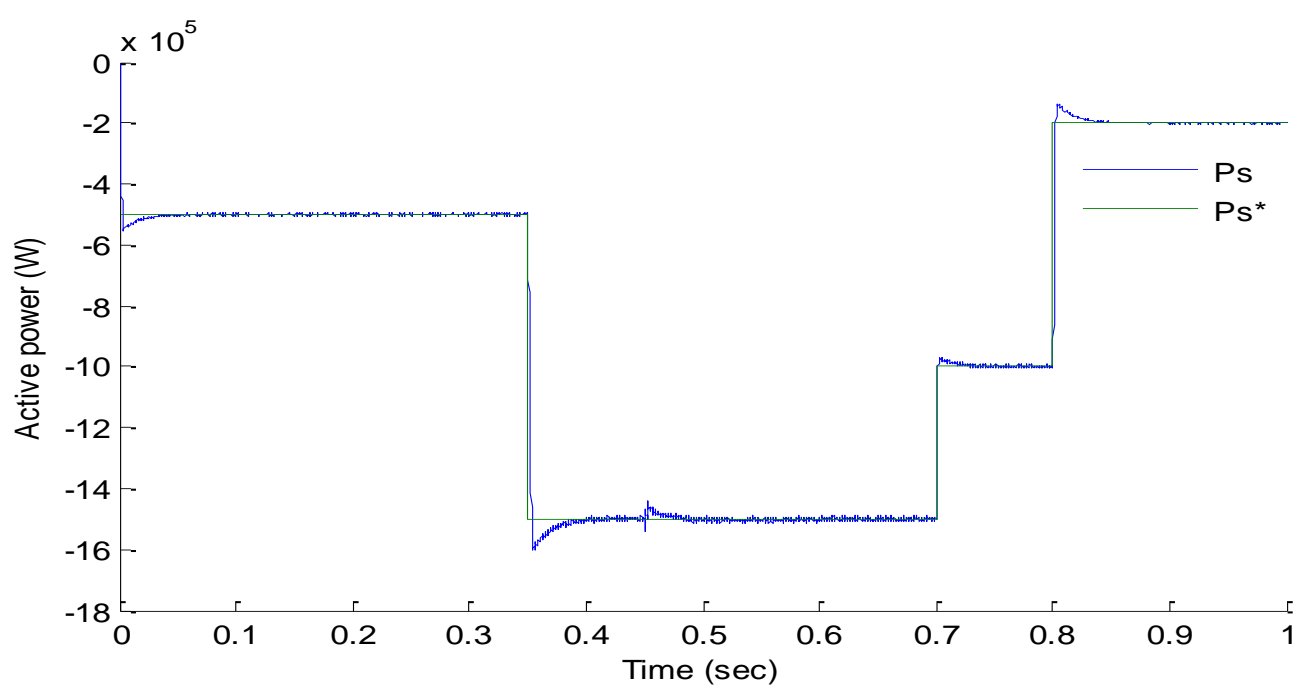

(a) active power response

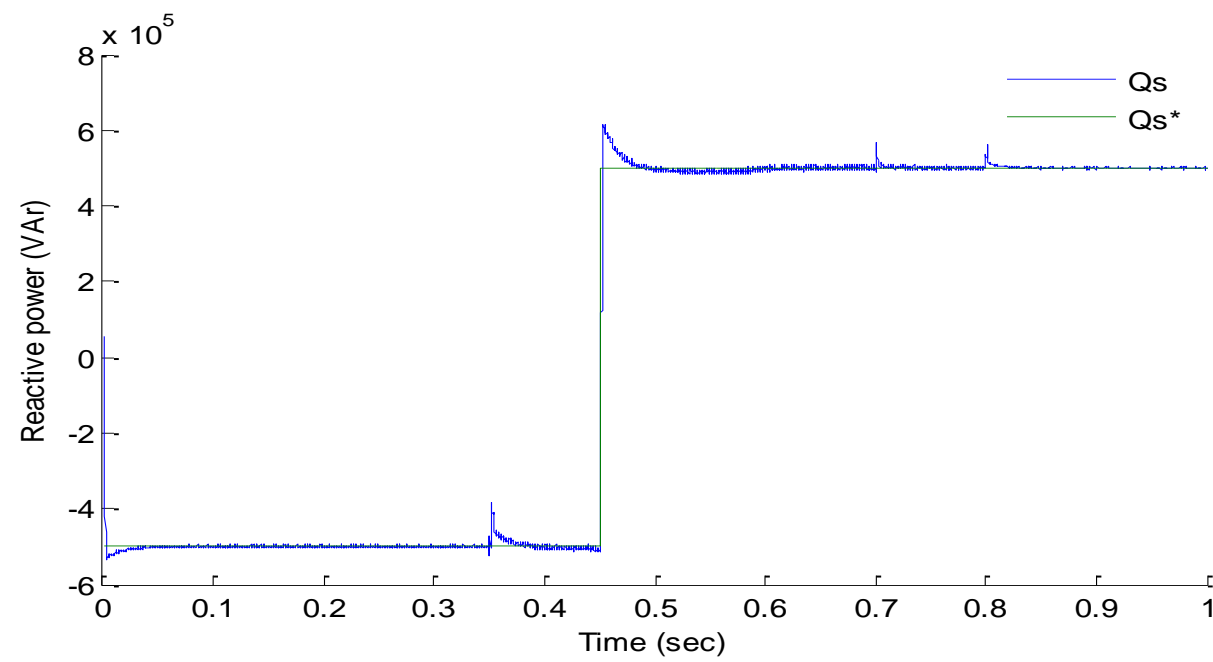

(b) reactive power response

Figure 6. Simulation results of the robustness test against parameters variations of DFIG for the input-output feedback linearization control 


\section{Conclusion}

In this paper it has been presented a robust nonlinear control strategy based on input-output linearization control, allowing an independent control of the active and reactive stator powers of the DFIG, driven by a variable speed wind turbine. The performances obtained by this control strategy are very satisfactory even in the presence of parameters variations as shown by the trajectory tracking and the fast convergence of the measured variables towards their desired references. Moreover, this control strategy has a very low harmonic distortion rate compared to other nonlinear control strategies such as sliding mode control technique. Finally, the proposed control strategy presented in this paper is a very simple robust control algorithm and has the advantage of being easily for a real time implementation.

\section{Appendix}

Table 1. Wind turbine parameters

\begin{tabular}{c|c|c}
\hline Parameter & Rated Value & Unit \\
\hline Rated power, $P_{n}$ & 1.5 & MW \\
\hline Blade radius, $R$ & 35.25 & $\mathrm{~m}$ \\
\hline Number of blades & 3 & - \\
\hline Gearbox ratio, $G$ & 90 & - \\
\hline Total moment of inertia, $J$ & 1000 & $\mathrm{~kg} \cdot \mathrm{m}^{2}$ \\
\hline Viscous friction coefficient, $f_{r}$ & 0.0024 & $\mathrm{~N} \cdot \mathrm{m} \cdot \mathrm{s}^{-1}$ \\
\hline Nominal wind speed, $v$ & 12 & $\mathrm{~m} / \mathrm{s}$ \\
\hline
\end{tabular}

Table 2. Doubly fed induction generator parameters

\begin{tabular}{c|c|c}
\hline Parameter & Rated Value & Unit \\
\hline Stator rated voltage, $V_{s}$ & $398 / 690$ & $\mathrm{~V}$ \\
\hline Rotor rated voltage, $V_{r}$ & $225 / 389$ & $\mathrm{~V}$ \\
\hline Rated current, $I_{n}$ & 1900 & $\mathrm{~A}$ \\
\hline Stator rated frequency, $f$ & 50 & $\mathrm{~Hz}$ \\
\hline Stator inductance, $L_{s}$ & 0.0137 & $\mathrm{H}$ \\
\hline Rotor inductance, $L_{r}$ & 0.0136 & $\mathrm{H}$ \\
\hline Mutual inductance, $L_{m}$ & 0.0135 & $\Omega$ \\
\hline Stator resistance, $R_{s}$ & 0.012 & $\Omega$ \\
\hline Rotor resistance, $R_{r}$ & 0.021 & - \\
\hline Number of pair of poles, $p$ & 2 & \multicolumn{2}{|c}{} \\
\hline
\end{tabular}

\section{References}

[1] H. Mesaiahmed, Y. Djeriri, A. Bentaallah and A. Mahmoudi, "Comparative study between pi and fuzzy pi controllers for DFIG integrated in variable speed wind turbine,"International Journal of Energetica, Vol. 4, No. 2, pp. 08-13, 2019.

[2] Z. Boudjema, A. Meroufel, E. Bounadja and Y. Djeriri, "Nonlinear control of a doubly fed induction generator supplied by a matrix converter for wind energy conversion systems,"Journal of Electrical Engineering, Vol. 13, No. 4, pp. 60-68, 2013.

[3] L. Ouada, B. Sebti, "Comparative Study Between Fuzzy and Sliding Mode Control Based on a BDFIG,"International Journal of Energetica, Vol. 4, No. 2, pp. 01-07, 2019. 
[4] A. Bouyekni, R. Taleb, Z. Boudjema and H. Kahal, "A second-order continuous sliding mode based on DPC for wind-turbine-driven DFIG,"Journal of Electrical Engineering and Computer Science, Vol. 85, No. 2, pp. 29-36, 2018.

[5] G. Tapia, A. Tapia, and J. X. Ostolaza, "Proportional-integral regulator based approach to wind farm reactive power management for secondary voltage control,"IEEE Trans. Energy Conversion, Vol. 22, pp. 488-498, 2007.

[6] L. Zhang, X. Cai and J. Guo, "Simplified input-output linearizing and decoupling control of wind turbine driven doubly-fed induction generators," IEEE 6th International Power Electronics and Motion Control Conference, IPEMC2009, pp. 632-673, 2009.

[7] A. F. Payam, "An Adaptive Input-Output Feedback Linearization Controller for Doubly-Fed Induction Machine Drives," Serbian Journal of Electrical Engineering, Vol. 5, No. 1, pp. 139-154, 2008.

[8] K. M. Haneesh, "Control of Doubly Fed Induction Generator Based Wind Energy Conversion Systems Using Feedback Linearization,”Advances in Natural and Applied Sciences, Vol. 10, No. 4, pp. 233-238, 2016.

[9] A. Bennouk1, A. Nejmi and M. Ramzi, "Feedback Linearization Control of Wind Turbine Based on PMSG,"International Journal of Emerging Technology and Advanced Engineering, Vol. 5, No. 3, pp433-438, 2015.

[10] Y. Djeriri, A. Meroufel, A. Massoum and Z. Boudjema, "A comparative study between field oriented control strategy and direct power control strategy for DFIG,"Journal of Electrical Engineering, Vol. 14, No. 2, pp. 169-178, 2014. 